\title{
Liposomal Curcumin Targeting Endometrial Cancer Through the NF-kB Pathway
}

\author{
Hanzi Xua,b Zhen Gong ${ }^{\mathrm{c}}$ Siying Zhou ${ }^{\mathrm{a}}$ Sujin Yang ${ }^{\mathrm{d}}$ Dandan Wang ${ }^{\mathrm{d}}$ \\ Xiu Chen ${ }^{d}$ Jiaqi Wu ${ }^{e}$ Liucheng Liu ${ }^{f}$ Shanliang Zhong ${ }^{b}$ Jianhua Zhao ${ }^{b}$ \\ Jinhai Tang ${ }^{a, d}$
}

aThe First School of Clinical Medicine, Nanjing University of Chinese Medicine, Nanjing, bjiangsu Institute of Cancer Research, Jiangsu Cancer Hospital, The Affiliated Cancer Hospital of Nanjing Medical University, Nanjing, 'Department of Gynecology, The Affiliated Obstetrics and Gynecology Hospital of Nanjing Medical University, Nanjing Maternity and Child Health Care Hospital, Nanjing, 'Department of General Surgery, the First Affiliated Hospital with Nanjing Medical University, Nanjing, Institute of Translational Medicine, College of Biotechnology and Pharmaceutical Engineering, Nanjing Tech University, Nanjing, 'Department of Pharmacy, Jiangsu Aosakang Pharmaceutical Co. Ltd., Nanjing, China

\section{Key Words}

Endometrial carcinoma $\cdot$ Liposomal curcumin $•$ NF-KB

\begin{abstract}
Background/Aims: Emerging evidence suggests that curcumin possesses chemopreventive properties against various cancers. However, its poor bioavailability limits its clinical application. In this study, we aimed to utilize encapsulation in liposomes (Lipo) as a strategy for the clinical administration of curcumin for endometrial carcinoma (EC). Methods: Curcumin was encapsulated in a liposomal delivery system to prepare a formulation of liposomal curcumin (LC). EC cell lines Ishikawa and HEC-1 were treated with the compound and cell proliferation was measured using MTT assay. Hoechst 33258 staining assay and flow cytometry were used to detect apoptosis of the cells. Wound healing and cell invasion assays were employed to monitor cell motility. Underlying target signaling, such as NF-KB, caspases, and MMPs, were further studied via GRT-PCR and western blot. Thereafter, a zebrafish model was used to assess the toxicity of LC. Finally, a zebrafish transplantation tumor model of EC was grown and treated with LC. Tumors were monitored and harvested to study the expression of NF-KB. Results: The formation of LC was successfully developed with excellent purity and physical properties. In vitro, LC resulted in dose-dependent inhibition of proliferation, induction of apoptosis, and suppression of Ishikawa and HEC-1 cell motility. LC treatment also suppressed the activation and/or expression of NF- $\mathrm{kB}$, caspase-3, and MMP-9. No demonstrable toxicity was found in the zebrafish model and tumors were suppressed after treatment with LC. PCR analysis also showed down-regulated expression of NF-KB. Conclusions: LC was successfully

H. Xu and Z. Gong contributed equally to this study.

\begin{tabular}{ll}
\hline Jinhai Tang & The First School of Clinical Medicine, Nanjing University of Chinese Medicine \\
& Nanjing, 210023 (China) \\
& Tel. +862583283364, Fax +862583283364, E-Mail jinhai_tang2017@163.com
\end{tabular}
\end{abstract}


prepared and played biological roles against EC probably through negative regulation of the NF-KB pathway in vitro and in vivo, which demonstrates its potential therapeutic effects in EC.

(C) 2018 The Author(s)

Published by S. Karger AG, Basel

\section{Introduction}

Endometrial carcinoma (EC) is one of the most common gynecological malignancies worldwide, with an estimated 61, 380 new cases (twice the sum of cervical and ovarian cancer cases) and 10, 920 deaths in the United States in 2017 [1]. In China, the incidence of EC has also increased over the past few decades, with the overall mortality rate of EC more than doubling during this period of time [2]. In large cities such as Beijing, EC has become the most common female reproductive system malignancy [3]. Despite the fact that more than $70 \%$ cases are diagnosed at an early stage, as many as $28 \%$ of patients have regional or distant metastasis [4]. Currently, the main treatment for this type of cancer is surgical resection. Meanwhile, chemotherapy supplemented by whole pelvic external beam radiotherapy is the key procedure for improving the survival rate of patients with clinical stages III/IV. Unfortunately, the prognosis is unsatisfactory, especially for patients at these stages, and the 5-year survival rate is approximately $25-45 \%[5]$. Moreover, $15 \%$ of patients with EC exhibiting an aggressive phenotype do not benefit from any therapeutic approaches used to treat this cancer [6]. Thus, it is important to find more efficient agents for the effective management of EC.

Curcumin (diferuloylmethane), commonly known as turmeric, is derived from the rhizome of the plant Curcuma longa. Due to its remarkable nontoxic nature, curcumin, as a Chinese herbal medicine, is widely used and exhibits an extensive range of bioactivities, particularly chemopreventive and therapeutic properties against numerous tumors including bladder, cervical, lung, pancreatic, and colorectal cancers [7]. Recently, Chen et al. reported the anti-metastatic effect of curcumin against EC cancer cells in vitro [2]. However, the clinical efficacy of curcumin is extremely limited because it has poor oral bioavailability [8], low water solubility, instability in gastrointestinal fluids and/or alkaline/higher $\mathrm{pH}$ conditions, and rapid systemic elimination [9].

Various strategies have been utilized to overcome the limitations of curcumin to enable its therapeutic application, such as complexation with biodegradable microspheres, hydrogels, and polymeric nanoparticles $[9,10]$. Among them, numerous studies have shown that the incorporation of curcumin into liposomes significantly increases its bioavailability [11, 12]. Liposomal curcumin (LC) therefore represents a promising drug delivery system that could overcome the pharmacokinetic and bioavailability limitations of curcumin.

In this study, we aimed to elucidate the antitumor effects and underlying mechanisms of $\mathrm{LC}$ against $\mathrm{EC}$ in vitro and in vivo.

\section{Materials and Methods}

\section{LC preparation}

Curcumin was obtained from Sigma-Aldrich (Sigma, USA). LC preparation was carried out by the protocol as described previously [12]. Briefly, the lipids and curcumin (Soybean phosphatidylcholine: cholesterol: curcumin $=2 \mathrm{~g}: 350 \mathrm{mg}: 100 \mathrm{mg})$ were thoroughly mixed in dichloromethane $(200 \mathrm{ml})$ and the solvent was removed. After that, $100 \mathrm{ml}$ phosphate-buffered saline (PBS) was added (pH 7.0) and agitated $(3000 \mathrm{rpm})$ at a temperature of $45^{\circ} \mathrm{C}$ for $40 \mathrm{~min}$. Finally the suspensions were disrupted by filtering through $0.4,0.2$ and 0.1 um polycarbonate filters. Content determination was assayed by High-performance liquid chromatography (HPLC) according to the general principle of Chinese pharmacopoeia (2015 edition, part 4, 0512). Stock solutions were prepared by dissolving individual compounds in Methanol (standard curcumin: $10 \mu \mathrm{g} / \mathrm{ml}$ ) and samples (standard curcumin and 1:200 diluted LC) were injected in triplicate into the HPLC (Shimadzu, LC-20AT, Japan) for detection. The isocratic condition using mobile phase composed of $48 \%(\mathrm{w} / \mathrm{w})$ ace-tonitrile and $52 \%$ of $4 \%(\mathrm{w} / \mathrm{w})$ glacial acetic acid solution. The injected amount onto 


\section{Cellular Physiology Cell Physiol Biochem 2018;48:569-582 and Biochemistry Published onIIne: July 18, $2018 \quad \begin{aligned} & \text { DOI: 10.1159/000491886 } 2018 \text { The Author(s). Published by S. Karger AG, Basel } \\ & \text { www.karger.com/cpb }\end{aligned}$}

Xu et al.: Liposomal Curcumin Targeting Endometrial Cancer

chromatographic column is $5 \mu \mathrm{l}$ and with a flow rate of $1.0 \mathrm{ml} / \mathrm{min}$, and the detection of curcumin was performed at $430 \mathrm{~nm}$. The sample $(1 \mathrm{mg} / \mathrm{ml})$ was stored at $2^{\circ} \mathrm{C}-8^{\circ} \mathrm{C}$ and warmed up to room temperature before use.

\section{Cell lines and culture condition}

Human endometrial carcinoma cell lines Ishikawa and HEC-1 were purchased from Sigma-Aldrich (Sigma, USA) and the cell bank of the Chinese Academy of Science (Shanghai, China) respectively, maintained according to the provider's instructions in DMEM (KeyGEN, Jiangsu, China), and supplemented with 10\% fetal bovine serum(FBS) (Tianhang Biotechnology, Zhejiang, China) and penicillin-streptomycin (100 units/ $\mathrm{ml}$ and $100 \mu \mathrm{g} / \mathrm{ml}$ ). The cells were incubated on 100-mm dishes and grew in a humidified atmosphere at 37 ${ }^{\circ} \mathrm{C}$ under $5 \% \mathrm{CO}_{2}$. Cells were plated for $24 \mathrm{~h}$, then treated with the experimental agents as indicated.

\section{Cell Proliferation Analysis}

Cell viability was determined by a colorimetric 3-(4, 5-dimethylthiazol-2-yl) 2, 5-diphenyltetrazolium bromide (MTT) assay in accordance with previously described protocols. Briefly, cells were plated in 96well culture plates and then treated for 24 hours with various concentrations of LC. The cells were then washed twice with PBS and incubated with $20 \mu \mathrm{l}$ of a $5 \mathrm{mg} / \mathrm{ml}$ MTT solution (Sigma, USA) for 4 hours at 37 ${ }^{\circ} \mathrm{C}$ before the culture medium was removed. Then, $150 \mu$ l dimethylsulfoxide (DMSO) (AMRESCO, America) per well was added and mixed in order to guarantee cytolysis and dissolution of the formazan crystal. The absorbance at $490 \mathrm{nM}$ was eventually measured through a microplate reader (CliniBio 128; ASYS Hitech, Eugendorf, Austria). The inhibitory rate of cell proliferation was calculated by the following formula: Inhibition rate $(I R)=[1-($ ODtreated $/$ ODcontrol $) \times 100 \%]$. The concentration at which cell growth were inhibited by $15-20 \%$ (IC15-20), 50\% (IC50) was calculated by nonlinear regression fit of the mean values of the data obtained in triplicate independent experiments.

Cell Apoptosis Analysis -Hoechst 33258 staining assay

Cells were processed and images acquired as described previously [13]. Briefly, EC cells were seeded and treated for 24 hours with 0, IC15-20 of LC, washed with PBS, fixed with 4\% formaldehyde in phosphatebuffered saline (PBS) for $10 \mathrm{~min}$, stained by Hoechst 33258 (10 mg/L, Sigma, USA) for 1 hour, and subjected to fluorescence microscopy. After treatment with troglitazone, morphologic changes, including nuclear fragment and chromatin condensation, were observed.

\section{Cell Apoptosis Analysis -Flow assay}

Cell apoptosis was detected using an Annexin-V-APC apoptosis detection kit (BD Pharmingen, America). Cells were exposed to different concentrations of LC $(0 \mu \mathrm{M}$, IC15-20, IC50) for 24 hours. The subsequent steps were performed according to the manufacturer's protocol. Simply, cells were trypsinized, washed twice in ice-cold PBS, and resuspended in $400 \mu \mathrm{L}$ of $1 \times$ binding buffer. A total of $5 \mu \mathrm{L}$ of annexin V-FITC and $5 \mu \mathrm{L}$ PI were added to the cells. After incubation at room temperature for 15 minutes in the dark, cells were then analyzed by a flow cytometer (FACSVerse/Calibur/AriaIISORP, BD, USA).

\section{Wound healing assay}

Wound healing assay was performed as described previously [2,14]. Briefly, EC cells were seeded to nearly 70\% confluence in monolayer 6-well plates containing 10\% FBS medium. After that, the monolayer was scratched with a $10 \mu \mathrm{L}$ pipette tip and the cells were incubated with various concentrations of LC for 24 hours. The wounded areas were monitored by inverted Leica phase-contrast microscope (Leica DFC 300 FX) and the assays were performed in triplicate.

\section{Cell invasion assay}

Cell invasion assays were conducted using transwell chambers ( $8 \mu \mathrm{m}$ pore; BD Biosciences, Franklin Lakes, NJ, USA) as described previously ${ }^{[2,14]}$. Briefly, cells were seeded in a 6-well plate and pretreated for 24 hours with various concentrations of LC. After that, cells were replated at a density of $2.5 \times 10^{4}$ cells per invasion chamber (BD Biosciences, Franklin Lakes, NJ, USA) in serum-free media. After that, serumcontaining media were used as a chemoattractant and placed outside of the chamber. Twenty-four hours later, noninvading cells were removed from inside the chamber. Cells on the exterior of the chamber were fixed, stained, visualized and counted. The assays were performed in triplicate. 


\section{Cellular Physiology Cell Physiol Biochem 2018;48:569-582 \begin{tabular}{l|l} 
and Biochemistry Published on/Ine:July 18, 2018 & $\begin{array}{l}\text { (c) } 2018 \text { The Author(s). Published by S. Karger AG, Basel } \\
\text { www.karger.com/cpb }\end{array}$ \\
\hline
\end{tabular}}

Xu et al.: Liposomal Curcumin Targeting Endometrial Cancer

\section{Real-time quantitative polymerase chain reaction assay (RT-qPCR)}

We collected cells treated with various concentrations of LC for 24 hours. Total RNA was extracted using RNA simple Total RNA kit (TIANGEN BIOTECH, Beijing, China) according to the manufacturer's instructions. The concentration and quality of the RNA were measured using the UV absorbance at 260 and $280 \mathrm{~nm}(260 / 280 \mathrm{~nm})$ on Nanodrop 2000 spectrophotometry (Thermo Scientific, USA). $500 \mathrm{ng}$ of total RNA was reverse transcribed by using BuSuperScript RT Kit (Biouniquer Technology, Nanjing, China) following the manufacturer's instructions. For determination of mature mRNA expression levels, RT-qPCR was then performed on LightCycler®480 (Roche, Switzerland) with SYBR Green PCR Master Mix (Roche, Australia). Cycling parameters were set up as follows: $95^{\circ} \mathrm{C}$ for 10 min followed by 40 cycles at $95^{\circ} \mathrm{C}$ for $15 \mathrm{~s}$ and 60 ${ }^{\circ} \mathrm{C}$ for $30 \mathrm{~s}$.

Primers used to amplify NF- $\mathrm{kB}$ and $\beta$-actin were purchased from Springen Biotechnology (China). All the samples were analyzed in triplicate for each specific gene. The REST-2009 program [15] was used to calculate the relative changes in NF- $\mathrm{KB}$ mRNA compared with the housekeeping gene ( $\beta$-actin). The primer pairs used are listed as follows: NF- $\kappa B$ Forward Primer ( $\left(5^{\prime}-3^{\prime}\right)$ : AAGAGTCCTTTCAGCGGACC, Reverse Primer (5'-3'): GCCCCCAGGTCTTCATCATC. $\beta$-actin Forward Primer $\left(5^{\prime}-3^{\prime}\right)$ : CACCTTCTACAATGAGCTGCGTGTG, Reverse Primer (5'-3'): ATAGCACAGCCTGGATAGCAACGTAC.

\section{Western Blot Analysis}

Western blot analysis to assess protein expression was performed as previously described [16]. Primary antibodies included anti-NF- $\mathrm{KB}$ (targeting p65), anti-Caspase-3 (targeting uncleaved and cleaved form), anti-MMP-9 (Cell Signaling Technology, USA), anti- $\beta$-actin (Proteintech, USA) and anti- histone H3 (Beyotime, China). Briefly, total proteins from cells were extracted using a radio immunoprecipitation assay (RIPA) lysis buffer [16] (Biouniquer Technology, China) referring to the manufacturer's instructions, and nuclear protein preparation was done using a nuclear extract kit according to the manufacturer's protocol (Beyotime, China)[17]. Protein content was estimated with Nanodrop 2000 spectrophotometry (Thermo Scientific, USA), and then proteins were mixed with sodium dodecyl sulfate-polyacrylamide gels (SDS-PAGE) buffer (Beyotime) and boiled for 5 min. Equal amounts of proteins were separated by electrophoresis on 10\% SDS-PAGE and transferred to polyvinylidene difluoride (PVDF) membranes (Sigma, USA). After blocking in 5\% nonfat milk powder for $2 \mathrm{~h}$, the membranes were then probed with the corresponding primary antibodies in TBST plus $5 \%$ milk overnight at $4{ }^{\circ} \mathrm{C}$. The following day, the PVDF membranes were washed with Tween 20/TBS (TBST) three times (10 min per wash) and incubated with appropriately a diluted horseradish peroxidase-linked secondary antibody at room temperature for $1 \mathrm{~h}$. After washing with TBST, protein bands were visualized by enhanced chemiluminescence (ECL) plus kit (Biouniquer Technology, CO, LTD).

\section{In vivo Analysis}

Wild-type zebrafish (Danio rerio; Tubingen line) were obtained from Model Animal Research Center of Nanjing University and were kept at $28.5^{\circ} \mathrm{C}$ as described previously [18]. Fertilized zebrafish eggs of the transgenic strain expressing green fluorescent protein (GFP) under the flk-1 promoter (flk-1: GFP) were used for in vivo imaging as previously described [19]. The age of the embryos is indicated as hours post fertilization (hpf). All zebrafish studies were reviewed and approved by the Institutional Animal Care and Use Committee at Nanjing University of Chinese Medicine.

\section{Toxicity Assay}

Embryos at $2 \mathrm{hpf}$ were randomly distributed in 24-well plate at a density of 20 embryos/well, containing $1 \mathrm{~mL}$ of embryo medium per well. Zebrafish embryos at 48 hpf were treated with various concentrations (final concentration) of LC. Lipo, and $30 \mu \mathrm{M}$ (final concentration) of curcumin were used as negative (vehicle) and positive control during the assays. Embryo mortality was monitored, and any dead embryos were removed daily during the whole experiment. The length of each embryo is determined based on measurements from the anterior-most portion of the head to the tip of the tail along the body axis using a dissecting microscope (SMZ745T, Nikon, Japan). 3 days later after treatment, survival rate and body length were assessed. Each treatment was performed in triplicate. 


\section{Cellular Physiology Cell Physiol Biochem 2018;48:569-582

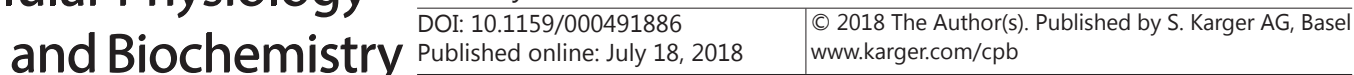 \\ Xu et al.: Liposomal Curcumin Targeting Endometrial Cancer}

Zebrafish Tumor Model Assay

Embryos were processed as described previously [19]. Briefly, EC cells were cultured in $10 \mathrm{~cm}$ dishes, stained with $2 \mathrm{mg} / \mathrm{mL}$ of DiI (Invitrogen) and transferred into an injection needle $(0.75 \mathrm{~mm}$ internal- and $1.0 \mathrm{~mm}$ external-diameter). $5 \mathrm{~nL}$ of tumor cell solution containing approximate 200 tumor cells was injected into the perivitelline cavity of each $48 \mathrm{hpf}$ embryo using a microinjector (Narishige). The embryos were incubated for 1 hour at $28.5^{\circ} \mathrm{C}$ after the injection. All zebrafish embryos were incubated in housing-keeping water and treated with various concentrations (final concentration) of LC for 6 hours at $28.5^{\circ} \mathrm{C}$ Medium was renewed and kept throughout the experiment. The embryos were examined for tumorgenesis using a fluorescent microscope (Olympus) 3 dpi (day post injection, dpi) later. Total RNA was extracted from 10 treated or control embryos after homogenization, reverse transcribed, and subjected to RT-qPCR.

\section{Statistical analysis}

Numerical data were presented as the mean \pm SD, and a statistical evaluation was performed using one-way ANOVA followed by Dunnett's multiple comparison to differentiate the means of different groups. R-2.14.1 for Windows (www.r-project.org) software was employed to analyze all data. A p-value of less than 0.05 was considered significant.

\section{Results}

\section{Preparation and characterization of $L C$}

LC was prepared following the protocols described in the Methods. Standard curcumin and LC showed chromatographic peaks at 11.835 min (Fig. 1A) and 11.831 min (Fig. 1D), respectively, whereas the lipids (Fig. 1B) and accessory chemical reagents (Fig. 1C) had no peaks, which implied the successful formation of LC. The formulation was further characterized by particle size and zeta potential. Photon correlation spectroscopy revealed that LC exhibited a mean particle size of approximately $126.8 \mathrm{~nm}$ (Fig. 1E) with a narrow size distribution (polydispersity index, PDI $=0.057$ ). LC was negatively charged, with a final zeta potential of $-8.88 \mathrm{mV}$ (Fig. 1F). LC, curcumin solution, and liposome (from left to right) characteristics are shown in Fig. $1 \mathrm{G}$.

\section{Proliferation inhibition of LC on EC cell lines}

We used human EC cell lines Ishikawa and HEC-1 to investigate the effects of LC on cell viability. Suppression of cell proliferation was assessed by MTT assays. The results showed that exposure to varying doses of LC $(0-130 / 150 \mu \mathrm{M})$ for $24 \mathrm{~h}$ inhibited the growth of both cell lines in a concentration-dependent manner (Fig. 2A-B). LC concentrations varied between the two cell lines in terms of suppressing proliferation but HEC-1 cells seemed to be slightly more resilient. Based on regression fit analysis, the concentrations of LC that

Fig. 1. Preparation and characterization of LC. Note: (A-D) Chromatography of LC: Standard curcumin and LC showed a peak at 11.835th (A) and 11.831th (D) min respectively, whereas the Lipo (B) and accessorily chemical reagents (C) did no peak during the whole process. (E-F) Character of LC: the average particle size of LC (E) was approximately $126.8 \mathrm{~nm}$ with a narrow size distribution (PDI $=0.057$ ) and the final zeta potential of LC (F) was $-8.88 \pm 5.27 \mathrm{mV}$. (G) Photographs of LC, standard curcumin solution and Lipo solution (from left to right). Abbreviations: LC, Liposomal Curcumin; Lipo, liposome.

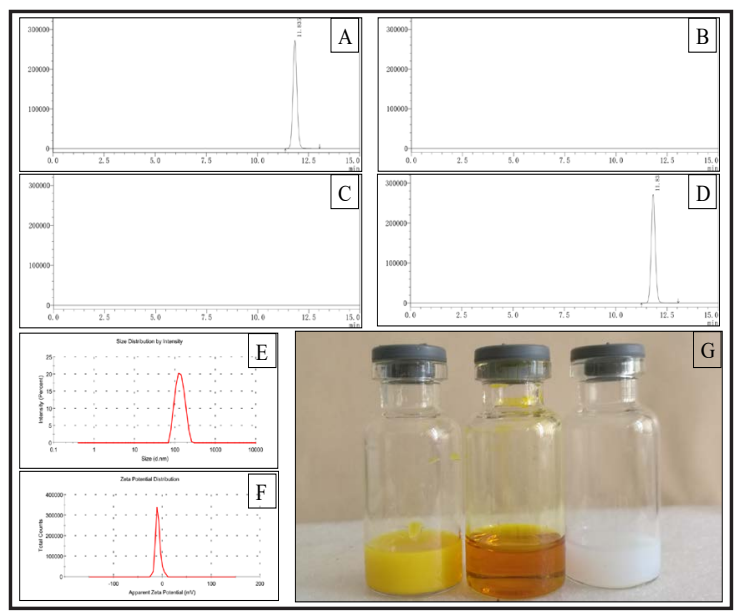




\section{Cellular Physiology

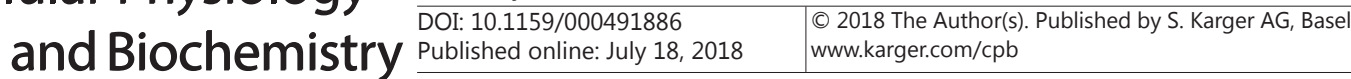

Fig. 2. LC inhibits proliferation/survival of EC cell lines in vitro. Note: EC cells (Ishikawa and HEC-1) were treated with various concentrations of LC for 24 hours. Effect of LC on cytotoxicity was assessed by the MTT (3-[4,5-dimethylthiazol-2-yl]2,5diphenyltetrazolium bromide) assay. Inhibition rates were calculated and values represent as the mean \pm SD of triplicate experiments. (left) cell line = Ishikawa, (right) cell line = HEC-1. Abbreviations: EC, endometrial carcinoma.

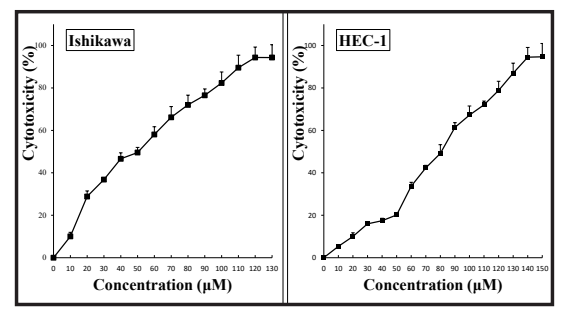

Fig. 3. LC induces apoptosis of EC cell lines in vitro. Note: Ishikawa (A-B) and HEC-1 (D-E) cells were treated with $\mathrm{LC}$ at $0 \mu \mathrm{M}$ (A and D) or $15 \mu \mathrm{M} / 30 \mu \mathrm{M}(\mathrm{B} / \mathrm{E})$ for 24 hours before staining with $10 \mathrm{mg} / \mathrm{L}$ Hoechst 33258 and then analyzed using a fluorescence microscope. The chromatin condensation and nuclear fragmentation were observed and the representative images were shown in (B) and (E). (C/F): EC cells were treated with various concentrations of LC (Control $=0 \mu \mathrm{M}$; Lipo as negative control and Curcumin as positive control, the corresponding concentration $=15 \mu \mathrm{M}$ for Ishikawa and $30 \mu \mathrm{M}$ for HEC-1) for 24 hours. The

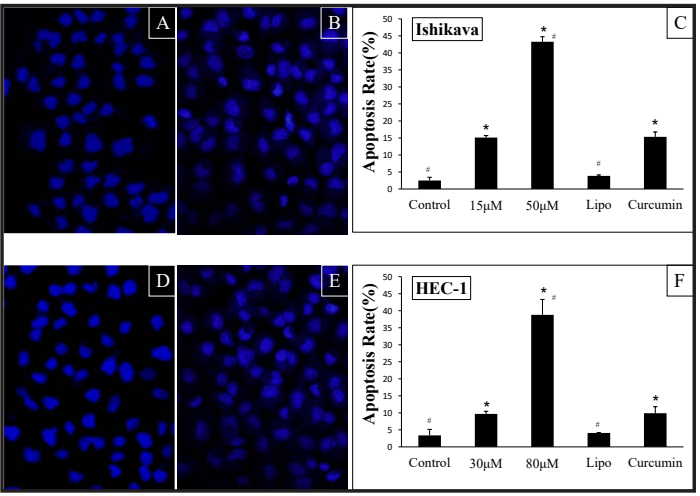
apoptosis rate was further analyzed by flow analysis and processed statistically. Data are expressed as mean \pm SD of triplicate experiments. ${ }^{*}=\mathrm{P}<0.05$, compared with Control; \#= $\mathrm{P}<0.05$, compared with $15 \mu \mathrm{M}$ or $30 \mu \mathrm{M}$ of LC treatment.

inhibited approximately 50\% of growth in Ishikawa and HEC-1 cells were $52.8 \mu \mathrm{M}$ and $80.8 \mu \mathrm{M}$, respectively. Therefore, $50 \mu \mathrm{M}$ and $80 \mu \mathrm{M}$, as IC50 values for these two cell lines, respectively, were used in the following experiments. At $15 \mu \mathrm{M}$ or $30 \mu \mathrm{M}$, LC only slightly inhibited the proliferation of Ishikawa and HEC-1 cells, respectively (approximately 15-20\%, IC15-20). Once the concentrations went below these levels, the suppression of proliferation was slight. This result agrees with that of Chen et al. [2], who demonstrated the inhibitory effect of LC on proliferation in EC cells. Thus, a concentration range of LC higher or lower than this was selected for the subsequent experiments.

\section{Apoptosis induction activity of LC on EC cell lines}

We performed two different tests to assess the effects of LC on the induction of apoptosis in EC cells. Ishikawa and HEC-1 cells were treated in the absence and presence of LC at concentrations representing IC15-20. After 24 h, the cells were stained with Hoechst 33258. Changes in cell nuclear morphology in LC-exposed cells were observed under a fluorescence microscope, and featured a marked increase in the quantity of apoptotic chromatin condensation and nuclear fragmentation (Fig. 3B and E).

Annexin V-FITC/PI was used to quantitatively determine the number of cells undergoing apoptosis. After LC treatment (the same concentrations of liposomes and curcumin served as negative and positive controls) for $24 \mathrm{~h}$, apoptosis was induced in a dose-dependent manner in both Ishikawa and HEC-1 cell lines (Fig. 3C and F). As expected, liposomes did not show any significant effect on the induction of apoptosis. The apoptosis rates were $15.12 \% \pm$ $0.59 \%$ and $43.25 \% \pm 1.48 \%$, respectively, in Ishikawa cells treated with LC IC15-20 (15 $\mu \mathrm{M})$ and IC50 $(50 \mu \mathrm{M})$, whereas the rates were $9.67 \% \pm 0.79 \%$ and $38.79 \% \pm 4.55 \%$ in HEC- 1 cells treated with $30 \mu \mathrm{M}$ and $80 \mu \mathrm{M}$ of LC, respectively. These results indicate that LC significantly induced apoptosis in EC cells in vitro. 


\section{Cellular Physiology Cell Physiol Biochem 2018;48:569-582 \begin{tabular}{ll|l} 
DOI: 10.1159/000491886 & O 2018 The Author(s). Published by S. Karger AG, Basel \\
www.karger.com/cpb
\end{tabular} Xu et al.: Liposomal Curcumin Targeting Endometrial Cancer}

Fig. 4. LC inhibits motility and invasiveness of EC cell line (Ishikawa) in vitro. Note: Ishikawa cells were scratched and then incubated in media containing 0 (Control), 5, $10 \mu \mathrm{M}$ of LC for $24 \mathrm{~h}$. Images were captured at 0 and $24 \mathrm{~h}$ after LC treatment. The representative images were shown in $(\mathrm{A})$. Ishikawa cells were pretreated with 0 (Control), $5,10 \mu \mathrm{M}$ of LC for $24 \mathrm{~h}$ and then seeded in the invasion chambers of a Transwell. Serum-containing media was added to outside of the chambers for $24 \mathrm{~h}$ to induce cell invasion. After $24 \mathrm{~h}$, noninvading cells were removed from inside the chamber and cells on the exterior of the chamber were fixed, stained and counted. The representative images were shown in (B). (C) The invasion of triplicate experiments is expressed as a ratio relative to the Control. ${ }^{*}=\mathrm{P}<0.05$, compared

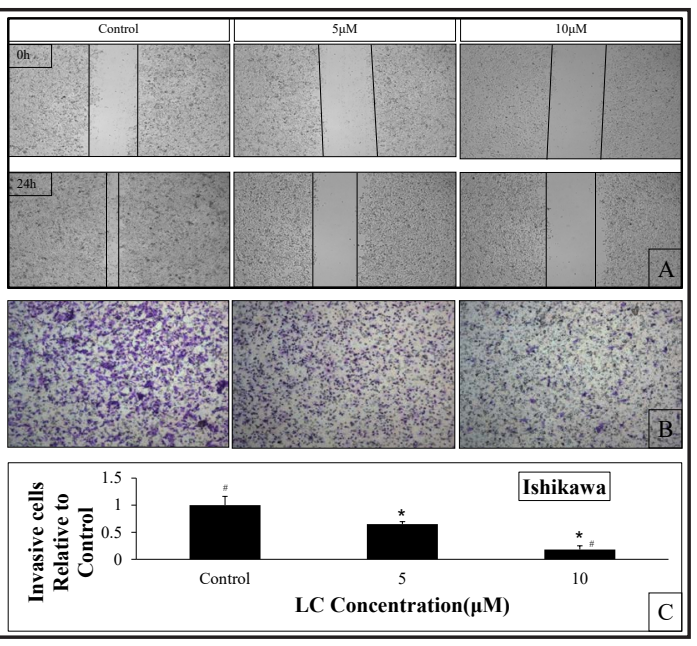
with Control; \# = P<0.05, compared with $5 \mu \mathrm{M}$ of LC treatment.

Fig. 5. LC inhibits motility and invasiveness of EC cell line (HEC-1) in vitro. Note: HEC-1 cells were scratched and then incubated in media containing 0 (Control), $5,10 \mu \mathrm{M}$ of LC for $24 \mathrm{~h}$. Images were captured at 0 and $24 \mathrm{~h}$ after LC treatment. The representative images were shown in (A). HEC-1 cells were pretreated with 0 (Control), 10, $20 \mu \mathrm{M}$ of LC for $24 \mathrm{~h}$ and then seeded in the invasion chambers of a Transwell. Serum-containing media was added to outside of the chambers for $24 \mathrm{~h}$ to induce cell invasion. After 24 $\mathrm{h}$, noninvading cells were removed from inside the chamber and cells on the exterior of the chamber were fixed, stained and counted. The representative images were shown in (B). (C) The invasion of triplicate experiments is expressed as a ratio relative to the Control. ${ }^{*}=\mathrm{P}<0.05$, compared with Control; $\#=$

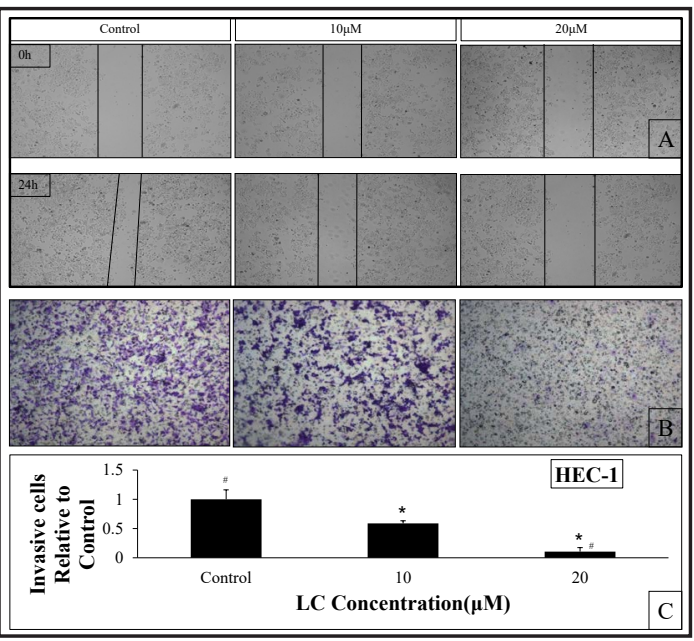
$\mathrm{P}<0.05$, compared with $10 \mu \mathrm{M}$ of LC treatment.

\section{LC-induced inhibition of cell motility in EC cell lines}

To study the effects of LC on EC cellular motility, cell migration assays were performed for the two cell lines. Cells were treated with the respective concentrations of $\mathrm{LC}$ for various periods of up to $24 \mathrm{~h}$. As shown in Figures 4/5A, continuous rapid migration was observed in the control groups, especially among Ishikawa cells, in which the wound was almost closed within $24 \mathrm{~h}$ of incubation. However, the migration of EC cells was significantly reduced following LC treatment at $5 \mu \mathrm{M}$ and $10 \mu \mathrm{M}$ (Ishikawa cells) or $10 \mu \mathrm{M}$ and $20 \mu \mathrm{M}$ (HEC-1).

A cell invasion assay was then performed to quantitatively determine the effect of LC on the invasiveness of EC cells. In a concentration-dependent manner, Ishikawa (Fig. 4B) and HEC-1 (Fig. 5B) cells both showed reduced invasive ability with treatment of $5 \mu \mathrm{M}$ and 10 $\mu \mathrm{M}$, or $10 \mu \mathrm{M}$ and $20 \mu \mathrm{M}$ of LC, respectively. Compared with the control groups (Figs. 4/5C), quantitative analysis indicated that the invasiveness of EC cells was reduced by $34.88 \%$ and $81.93 \%$ in Ishikawa cells and $41.3 \%$ and $89.57 \%$ in HEC-1 cells, respectively, indicating that LC significantly inhibited the migration and invasion of EC cells in vitro. 
Fig. 6. LC inhibits NF- $\kappa B$ and its downstream key molecules on EC Ishikawa cell line in vitro. Note: Ishikawa cells were treated with 0 (Control), 15, $50 \mu \mathrm{M}$ of LC and $15 \mu \mathrm{M}$ of curcumin, or 0 (Control), $5,10 \mu \mathrm{M}$ of LC for 24 hours. Cells were harvested and the mRNA level of NF- $\kappa \mathrm{B}$ was analyzed by PCR analysis and processed statistically. Data of triplicate experiments was expressed as a ratio relative to the Control and was shown in (A) and (B). ${ }^{*}=\mathrm{P}<0.05$, compared with the Control; $\#=$ $\mathrm{P}<0.05$, compared with $15 \mu \mathrm{M}$. The expression of nuclear NF- $\mathrm{BB}$ and cytoplasmic Caspase-3 and MMP-9 was detected through western blot analysis. The representative images were shown in

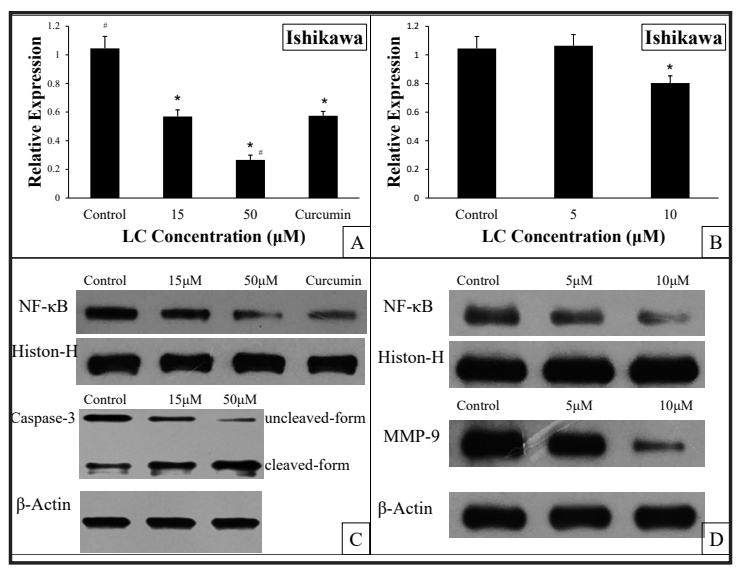
(C) and (D).

Fig. 7. LC inhibits NF- $\mathrm{B}$ and its downstream key molecules on EC HEC-1 cell line in vitro. Note: HEC1 cells were treated with 0 (Control), $30,80 \mu \mathrm{M}$ of $\mathrm{LC}$ and $30 \mu \mathrm{M}$ of curcumin, or 0 (Control), 10, $20 \mu \mathrm{M}$ of LC for 24 hours. Cells were harvested and the mRNA level of NF- $\kappa$ B was analyzed by PCR analysis and processed statistically. Data of triplicate experiments was expressed as a ratio relative to the Control and was shown in (A) and (B). ${ }^{*}=\mathrm{P}<0.05$, compared with the Control; $\#=\mathrm{P}<0.05$, compared with $30 \mu \mathrm{M}$. The expression of nuclear NF- $\mathrm{BB}$ and cytoplasmic Caspase-3 and MMP-9 was detected through western blot analysis. The representative images were shown in (C) and (D).

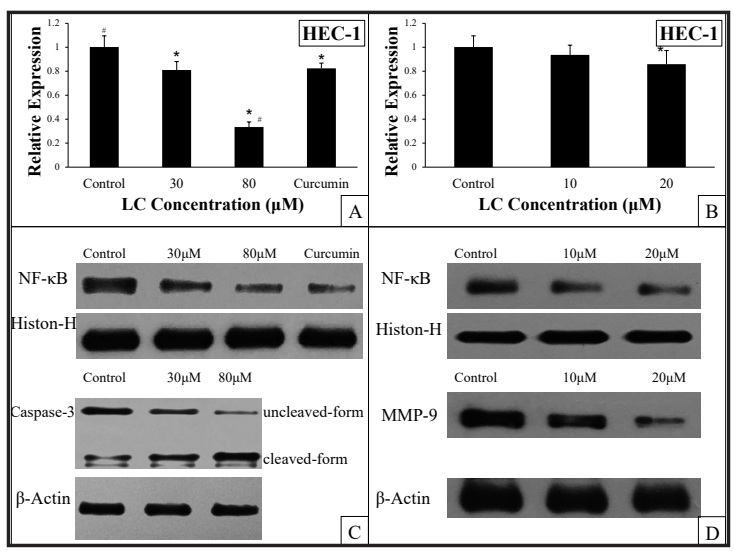

$N F-\kappa B$ pathway is involved in the activity of $L C$ on $E C$ cells

Since the NF- $\kappa$ B pathway is involved in the activities of curcumin, we performed RT-PCR and western blot analysis with a view to obtaining mechanistic insights into the effects of LC on EC cells. We measured the expression levels of NF- $\kappa B$ and its downstream molecules at mRNA or protein levels in EC cells treated with LC. As expected, the mRNA levels of NF$\kappa \mathrm{B}$ were down-regulated in a concentration-dependent manner in both Ishikawa (from 10 $\mu \mathrm{M}$ to $50 \mu \mathrm{M}$, Figs. 6A-B) and HEC-1 (from $20 \mu \mathrm{M}$ to $80 \mu \mathrm{M}$, Fig. 7A-B) cells treated with LC compared to untreated cells. Comparatively negative regulation of NF- $\kappa \mathrm{B}$ mRNA was found but this was not significant in either cell line treated with a low concentration of LC (5 $\mu \mathrm{M}$ for Ishikawa, Fig. 6B; $10 \mu \mathrm{M}$ for HEC-1, Fig. 7B). More importantly, the nuclear protein level of NF- $\mathrm{KB}$ was accordingly down-regulated in both cell lines, in a concentration-dependent manner (from $0 \mu \mathrm{M}$ to $50 \mu \mathrm{M}$ for Ishikawa and from $0 \mu \mathrm{M}$ to $80 \mu \mathrm{M}$ for HEC-1, Fig.s. 6/7C-D). Given that NF- $\mathrm{BB}$ is involved in the activities of LC in EC cells, we measured the downstream protein levels involved in cell apoptosis and invasion, including caspases and matrix metalloproteinases (MMPs), by western blot. Again, the protein levels of Caspase-3 (uncleaved form) and MMP-9 were significantly reduced in both Ishikawa (Fig. 6C-D) and HEC-1 (Fig. 7C-D) cells treated with LC. At the same time, Caspase-3 protein (cleaved-form) increased significantly (Figs. 6/7C). Thus, the results clearly indicated the role of LC in the down-regulation of proliferation, anti-apoptosis, and invasion through inhibition of the NF$\kappa \mathrm{B}$ pathways in vitro. 
Toxicity evaluation of LC in vivo

To evaluate the possible toxicity of LC, we analyzed the developmental phenotype, including survival rate and body length, of zebrafish embryos after exposure to different concentrations of LC. As shown in Fig. 8A, LC concentrations of up to $80 \mu \mathrm{M}$ for $6 \mathrm{~h}$ did not cause significant embryo death. The lengths of the embryos were not affected after exposure to $80 \mu \mathrm{M} \mathrm{LC}$ for up to $6 \mathrm{~h}$ (Fig. 8B). Putting these findings together, we considered that a 6-h treatment of LC did not have any toxic effects on zebrafish embryos; therefore, a 6-h treatment period was used in the subsequent experiments.

\section{$L C$ inhibited EC tumor growth in vivo via reducing $N F-\kappa B$ expression}

To investigate the anti-tumor activities of LC in EC in vivo, Dil-labeled EC cells (Ishikawa and HEC-1) were injected into the perivitelline cavities of zebrafish embryos at $48 \mathrm{~h}$ postfertilization and the embryos were then treated with LC. After $72 \mathrm{~h}$, LC had dramatically delayed tumor growth in zebrafish in a concentration-dependent manner $0-50 \mu \mathrm{M}$ for Ishikawa or $0-80 \mu \mathrm{M}$ for HEC-1; Fig. 9). However, zebrafish embryos treated with Lipo (negative control) had a large quantity of tumor cells in the subintestinal space and no significant inhibitory effects on tumor growth were found. Interestingly, as a positive control,

Fig. 8. Toxicity effect of LC in vivo. Note: Zebrafish embryos at $48 \mathrm{hpf}$ were treated with 0 (Control) and up to $80 \mu \mathrm{M}$ of LC for 6 hours and mortality and body length were monitored 3 days later. The zebrafish embryo survival rates and body length difference were shown in (A) and (B) respectively. ${ }^{*}=\mathrm{P} \geq 0.05$,

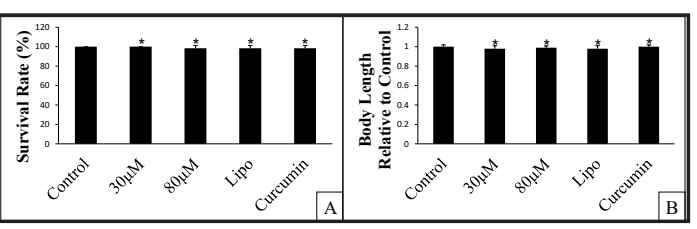
compared with the Control. Abbreviations: hpf, hours post fertilization.

Fig. 9. LC inhibits EC tumor growth in vivo. Note: Zebrafish embryos pre-injected with EC cells were treated with various concentrations of LC (Control $=0 \mu \mathrm{M}$; Lipo as negative control and Curcumin as positive control, the corresponding concentration $=15 \mu \mathrm{M}$ for Ishikawa and $30 \mu \mathrm{M}$ for HEC-1) for 6 hours and were further monitored and photographed 3 dpi later. The representative images of tumor (Red) were shown in the left part (upper left $=$ pre-injected with Ishikawa, down left $=$ pre-injected with HEC-1). Data of triplicate experiments was expressed as a ratio relative to the Control, processed statistically and shown in the right part. ${ }^{*}=\mathrm{P}<0.05$, compared with the Control);
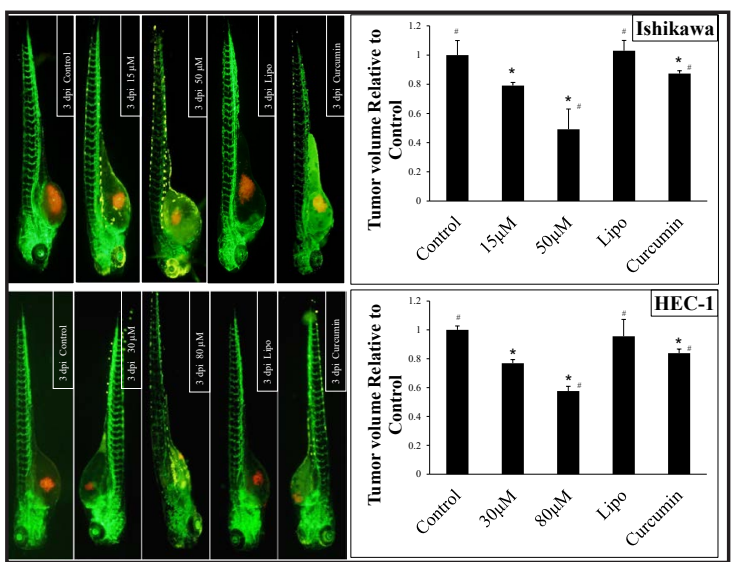
\# $=\mathrm{P}<0.05$, compared with $15 \mu \mathrm{M}$ or $30 \mu \mathrm{M}$ of $\mathrm{LC}$ treatment. Abbreviations: dpi, day post injection.

Fig. 10. LC reduces NF- $\kappa B$ expression of EC in vivo. Note: Zebrafish embryos pre-injected with EC cells were treated with various concentrations of LC (Control $=0 \mu \mathrm{M}$; Lipo as negative control and Curcumin as positive control, the corresponding concentration $=15 \mu \mathrm{M}$ for Ishikawa and $30 \mu \mathrm{M}$ for HEC-1) for 6

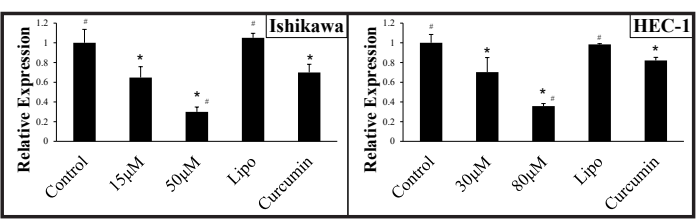
hours and were further incubated for 3 days. Total RNA was extracted from treated or control embryos and subjected to RT-qPCR. Data of triplicate experiments was expressed as a ratio relative to the Control, processed statistically and shown above. ${ }^{*}=\mathrm{P}<0.05$, compared with the Control); $\#=\mathrm{P}<0.05$, compared with $15 \mu \mathrm{M}$ or $30 \mu \mathrm{M}$ of LC treatment. 


\section{Cellular Physiology Cell Physiol Biochem 2018;48:569-582 \\ \begin{tabular}{l|l} 
DOI: 10.1159/000491886 & O 2018 The Author(s). Published by S. Karger AG, Basel \\
www.karger.com/cpb
\end{tabular}}

Xu et al.: Liposomal Curcumin Targeting Endometrial Cancer

curcumin $(15 \mu \mathrm{M}$ for Ishikawa or $30 \mu \mathrm{M}$ for HEC-1; Fig. 9) showed significant inhibitory effects on tumor growth compared with control, but comparatively weaker effects compared with LC at the same concentration.

After confirming the in vivo effects of LC, such as the inhibition of tumor growth in EC, the underlying mechanistic studies drew our attention. Given the above fact that EC tumor growth is probably dependent on the activation of NF- $\kappa \mathrm{B}$ pathways, we further examined whether LC could exert any effects on the signaling pathways by RT-PCR. Consequently, we found that LC dose-dependently reduced the mRNA levels of NF- $\mathrm{BB}(0-50 \mu \mathrm{M}$ for Ishikawa or $0-80 \mu \mathrm{M}$ for HEC-1; Fig. 10). Again, Lipo as a negative control had no effect on signaling. Curcumin, as the positive control (15 $\mu \mathrm{M}$ for Ishikawa or $30 \mu \mathrm{M}$ for HEC-1; Fig. 10), also dramatically reduced the NF- $\kappa B$ mRNA level but the effect was no different from the same concentration of LC. Together the data suggested that LC delayed EC tumor growth in vivo, and this phenomenon could be associated with the NF- $\kappa B$ signaling pathway.

\section{Discussion}

Advanced endometrial cancer has high mortality and poor prognosis [20], and chemoradiotherapy has limited effectiveness. A more serious problem for clinicians is that either commonly used first-line, or emerging chemotherapeutic drugs cause severe side effects and toxicity [21], which largely limits their clinical use and efficiency. To find safer therapeutic drugs for EC, especially for long-term use, researchers have recently turned to natural anti-tumor drugs containing active plant ingredients.

Curcumin, a lipid-soluble active ingredient of curcuma in traditional Chinese medicine, has diverse pharmacological effects against inflammation, oxidation, bacteria, and tumors [22]. Because of its abundance, low cost, and availability, it has become a promising antitumor drug for further exploitation and application and has been widely applied to antitumor experiments worldwide, which have shown significant achievements in preventing the occurrence, development, and metastasis of tumors [7]. Compared with other traditional chemotherapeutic drugs, curcumin has almost no apparent toxicity or side effects, which makes it a promising anti-tumor treatment. However, it has some serious limitations, such as low water solubility and absorption, extreme instability, and rapid metabolism and degradability, which reduce its bioavailability and restrict its direct clinical application as an anti-tumor drug.

To improve the bioavailability of curcumin and to better use its anti-tumor pharmacological effects in vivo, researchers have devoted efforts to drug-loading systems in vivo. In particular, drug delivery via colloid carrier systems, including liposomes, nanoemulsions, and nanoparticles [23], has become a pharmacological research focus. Like biomembranes, liposomes are composed of lipid membranes, including phospholipids and cholesterol. As a new drug delivery system, liposomes can significantly improve the water solubility and stability of drugs and increase their tissue compatibility and bioavailability.

The preparation and anti-tumor effects of LC have been validated in many fields, including head and neck tumors [24], lung cancer [25], breast cancer [10], pancreatic cancer [11], prostate cancer [26], and cervical cancer [27]. However, there have not been any relevant reports on EC so far. Thus, we attempted the preparation of LC, validated its activity against EC through experiments in vitro and in vivo, and thereby laid a foundation for its clinical application.

Specifically, based on the curcumin standard substance, we prepared LC according to our previous work [12]. The initial ratio was $2 \mathrm{~g}$ of soy lecithin:350 $\mathrm{mg}$ of cholesterol:100 mg of curcumin. High-performance liquid chromatography proved the high purity and other properties of LC including particle size $=126.8 \mathrm{~nm}$, zeta potential $=-8.88 \mathrm{mV} \pm 5.27 \mathrm{mV}$ and indicated its high water solubility and stability, required for clinical applications.

On this basis, we selected Ishikawa (high ER expression) and HEC-1 (low ER expression) EC cell lines as target cells and investigated the inhibitory effects of LC on proliferation 
in vitro. Our results were consistent with those of the study by Chen et al [2]., in that LC significantly inhibited the proliferation of both Ishikawa and HEC-1 cells, which indicated that LC completely retained the bioactive inhibitory effects of curcumin on cell proliferation in vitro.

Reports in the literature show that the anti-tumor effects of curcumin include not only the inhibition of tumor cell proliferation but also the induction of apoptosis [28]. Thus, we further tested whether LC could induce the apoptosis of EC cells. Consistent with these studies, fluorescence staining showed typical apoptotic morphological changes in the test group of both Ishikawa and HEC-1 cells. Flow apoptosis trials also indicated that, compared with the control groups, neither Ishikawa and HEC-1 cells treated with liposomes induced apoptosis in EC cells. At higher concentrations, LC more effectively induced cell apoptosis, and this was significantly different from the control group $(\mathrm{p}<0.05)$ but not from the sameconcentration curcumin group (positive control) ( $\mathrm{p} \geq 0.05$ ), indicating that LC could strongly induce the apoptosis of EC cells.

In addition to proliferation, curcumin in vitro inhibits the invasion and metastasis of EC cells $[2,29]$. Therefore, we further investigated whether LC would affect the invasion and metastasis of EC cells. Both wound healing and transwell trials showed that 5-10 $\mu \mathrm{M}$ or $10-20 \mu \mathrm{M}$ of LC could significantly inhibit the invasion and metastatic abilities of Ishikawa cells or HEC-1 cells, respectively, indicating that LC not only inhibits cell proliferation and induces cell apoptosis but also inhibits the invasive and metastatic bioactivities of EC cells.

Previous studies suggest that curcumin inhibits proliferation and induces apoptosis in various tumor cells to different extents and this may be attributed to its ability to downregulate the NF- $\kappa B$ signaling pathway $[11,30]$. Commonly there are two general pathways of activation, classical and alternative, for NF- $\mathrm{BB}$ signaling. In the alternative pathway, p52/ RelB heterodimers accumulate in the nuclei. In the classical pathway, NF- $\kappa B$ homodimers or heterodimers, mainly including p65 and p50, accumulate in the nuclei [31]. It is known that in the resting state, standard NF- $\mathrm{KB}$ (p50 and/or p65 dimers) binds via non-covalent bonds to profilin I $\mathrm{\kappa}$, forming an inactive p50-p65-I $\mathrm{B}$ trimer, which is dispersed among cytoplasts. When the NF- $\kappa$ B pathway is activated by external signals, I $\kappa B$ is phosphorylated, dissociates from the trimer, and is thereby hydrolyzed, which exposes the metathesis signals on the p50 subunit and the DNA binding sites on the p65 subunit. The NF- $\kappa$ B p50/p65 proteins then enter the nucleus and bind with specific proteins on the DNA module, thereby inducing the formation of specific mRNA and transcription regulation [32].

In light of these findings, we must discuss the mechanism underlying the above activities of LC. We first measured the mRNA levels of NF- $\kappa B$ after EC cells were treated with LC. It was found that LC significantly down-regulated the mRNA levels of NF- $\mathrm{BB}$ in a concentrationdependent way. Specifically, in Ishikawa cells, LC significantly downregulated the mRNA levels of NF- $\kappa \mathrm{B}$ once the concentration was no less than $10 \mu \mathrm{M}$. However, in HEC-1 cells, a concentration of $20 \mu \mathrm{M}$ was required. Thus, we further detected the specific protein level of nuclear NF- $\kappa B$ (p65). It was also found that, in both Ishikawa and HEC-1 cells, LC significantly reduced the expression of NF- $\kappa \mathrm{B}$ in a concentration-dependent manner (Ishikawa, 0-50 $\mu \mathrm{M}$; HEC-1, 0-80 $\mu \mathrm{M}$ ). Previous reports have shown that by regulating the activity of NF- $\kappa \mathrm{B}$ pathways, curcumin induces apoptosis and inhibits invasion and metastasis of tumor cells mainly because it affects the expression of the apoptosis pathway core molecules, that is, caspases and the invasion-metastasis key molecules, MMPs [11, 31]. Therefore, we further measured the expression of caspases and MMPs and found that in both Ishikawa and HEC1 cells, LC significantly affected the expression of Caspase-3 and MMP-9, depending on the concentration of NF- $\mathrm{KB}$ protein. Thus, we believe that the effect of LC on the bioactivity of EC cells may also be attributed to its ability to negatively regulate the NF- $\kappa B$ pathways. Specifically, it might down-regulate mRNA and/or the nuclear protein levels of NF- $\mathrm{KB}$, thereby negatively regulating the downstream core molecules, such as Caspase- 3 and MMP9.

Despite the operational simplicity and low costs of in vitro experiments, the anti-tumor effects may differ from those in vivo. Thus, in vivo experiments should also be performed. In 


\section{Cellular Physiology Cell Physiol Biochem 2018;48:569-582 \begin{tabular}{c|c|c|c|} 
DOI: 10.1159/000491886 & O 2018 The Author(s). Published by S. Karger AG, Basel \\
wwww.karger.com/cpb
\end{tabular} \\ Xu et al.: Liposomal Curcumin Targeting Endometrial Cancer}

our preliminary studies, we used the classical xenograft animal model (with SCID mice as the carrier, data not shown) as an in vivo research platform, which was finally abandoned due to high costs, long cultivation periods, and tedious operations. Owing to factors like low costs, short experimental periods (4-7 days), no evident immune system reactions, and clearly recognized transplanted-tumor cells [19], the zebrafish model-as a developing transplantation tumor model-has attracted our attention in recent years. Based on our recent experience with in vivo toxicology and anti-tumor activity studies using the zebrafish model [18], we finally selected this model as a platform to determine the in vivo effects of LC against EC.

To explore safety, we first applied LC (highest concentration $80 \mu \mathrm{M}$ ) to zebrafish for 0-24 h. Within $6 \mathrm{~h}$, the survival rates were not significantly different between the test groups, the control group, and the positive/negative control group, and were all up to $100 \%$. Therefore, we selected $6 \mathrm{~h}$ as the maximum treatment time, and further investigated the changes in zebrafish long shafts after treatment with LC. Again, no significant differences were found between the test, control, and positive/negative control groups. These results primarily indicated that LC is nontoxic and safe in zebrafish for up to $6 \mathrm{~h}$ of treatment.

We then transplanted EC cells into the zebrafish to generate tumor models and further investigated the inhibitory effects of LC on EC cells. The results were consistent with in vitro studies because LC inhibited EC tumor growth in a concentration-dependent manner. We finally collected the tumor cells from the zebra fish tumor models and measured the mRNA levels of NF- $\kappa$ B. Again, it was found that LC in vivo significantly down-regulated the mRNA levels of NF- $\kappa \mathrm{B}$ in a concentration-dependent way. Therefore, we concluded that the in vivo inhibitory effects of LC on EC may also be associated with an ability to negatively regulate the activity of the NF- $\kappa$ B pathway.

Considering that (1) p65 was down-regulated in the NF- $\kappa B$ subunits after LC treatment in the current study, and (2) the p65 subunit is required for the activation of classical NF- $\kappa B$ signaling, it is justifiable to believe that negative regulation of NF- $\kappa \mathrm{B}$ signaling was achieved at least via the classical pathway in the current study. Interestingly, compared with curcumin alone treatment, LC was not significantly different in its ability to downregulate NF- $\mathrm{B}$ mRNA levels (both in vivo and in vitro), and it showed better inhibition of EC growth in vivo than in vitro, indicating that, importantly, LC plays biological roles against EC in vivo that are probably not purely through negative regulation of the NF- $\mathrm{KB}$ pathway, but rather through additional mechanisms that should be further explored.

In summary, LC was successfully prepared and had biological effects against EC, probably through negative regulation of the NF- $\mathrm{KB}$ pathway (and its downstream key molecules) in vitro and in vivo, indicating its potential therapeutic effects in the treatment of EC, which should be further explored.

\section{Acknowledgements}

This study was sponsored by Jiangsu Province "six talent peak" Personal Training Project (NO2016-WSW-086) and Jiangsu Provincial Women and Children Health Research Project (F201762).

\section{Disclosure Statement}

The authors declare that they have no conflicts of interest to disclose. 


\section{Cellular Physiology Cell Physiol Biochem 2018;48:569-582

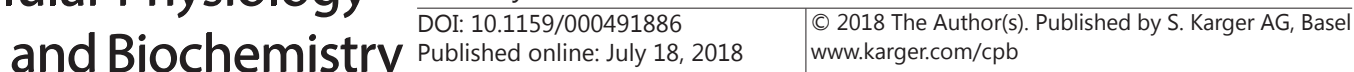

Xu et al.: Liposomal Curcumin Targeting Endometrial Cancer

\section{References}

1 Siegel RL, Miller KD, Jemal A: Cancer Statistics 2017 CA Cancer J Clin 2017;67:7-30.

2 Chen Q Gao Q, Chen K, Wang Y, Chen L, Li XU. Curcumin suppresses migration and invasion of human endometrial carcinoma cells. Oncology Letters 2015;10:1297-1302.

3 Wang SX, Chen Li, Dong KX, Diao XD, Sun XJ, Yan XH: Spectrum analysis of 2534 cases of malignant tumors in Miyun District, Beijing. J Prac Oncology 2013;28:81-84.

4 Sun KX, Chen Y, Chen S, Liu BL, Feng MX, Zong ZH, Zhao Y: The correlation between microRNA490-3p and TGF $\alpha$ in endometrial carcinoma tumorigenesis and progression. Oncotarget 2011;7:9236-9249.

5 Chen S, Sun KX, Liu BL, Zong ZH, Zhao Y: The role of glycogen synthase kinase-3beta (GSK-3beta) in endometrial carcinoma: A carcinogenesis, progression, prognosis, and target therapy marker. Oncotarget 2016;7:27538-27551.

6 Yeramian A, García V, Bergadà L, Domingo M, Santacana M, Valls J, Martinez-Alonso M, Carceller JA, Cussac AL, Dolcet X, Matias-Guiu X: Bioluminescence Imaging to Monitor the Effects of the Hsp90 Inhibitor NVPAUY922 on NF-kappaB Pathway in Endometrial Cancer. Mol Imaging Biol 2016;18:545-56.

7 Allegra A, Innao V, Russo S, Gerace D, Alonci A, Musolino C: Anticancer Activity of Curcumin and Its Analogues: Preclinical and Clinical Studies. Cancer Invest 2017; 35:1-22.

8 Liu W, Zhai Y, Heng X, Che FY, Chen W, Sun D, Zhai G: Oral bioavailability of curcumin: problems and advancements. J Drug Target 2016;24:694-702.

-9 Luo CQ, Xing L, Cui PF, Qiao JB, He YJ, Chen BA, Jin L, Jiang HL: Curcumin-coordinated nanoparticles with improved stability for reactive oxygen species-responsive drug delivery in lung cancer therapy. Int J Nanomedicine 2017;12:855-869.

10 Hasan M, Belhaj N, Benachour H, Barberi-Heyob M, Kahn CJ, Jabbari E, Linder M, Arab-Tehrany E: Liposome encapsulation of curcumin: physico-chemical characterizations and effects on MCF7 cancer cell proliferation. Int J Pharm 2014;461:519-528.

-11 Ranjan AP, Mukerjee A, Helson L, Gupta R, Vishwanatha JK: Efficacy of liposomal curcumin in a human pancreatic tumor xenograft model: inhibition of tumor growth and angiogenesis. Anticancer Res 2013;33:3603-3609.

12 Dai F, Zhang X, Shen W, Chen J, Liu L, Gao G: Liposomal curcumin inhibits hypoxia-induced angiogenesis after transcatheter arterial embolization in VX2 rabbit liver tumors. Onco Targets Ther 2015.8:2601-2611.

13 Han C, Gong Z, Hao L, Yang J, Hu J, Dong B, Fan T, Tang W, Teng G: Mechanism of monoclonal antibodycoupled Staphylococcus superantigen-A induced apoptosis in human bladder cancer cells. Cell Biochem Biophys 2011;61:679-684.

14 Zhang J, Yang F, Ding Y, Zhen L, Han X, Jiao F, Tang J: Overexpression of L1 cell adhesion molecule correlates with aggressive tumor progression of patients with breast cancer and promotes motility of breast cancer cells. Int J Clin Exp Pathol 2015;8:9240-7.

15 Leduc V, Legault V, Dea D, Poirier J: Normalization of gene expression using SYBR green qPCR: a case for paraoxonase 1 and 2 in Alzheimer's disease brains. J Neurosci Methods 2011;200:14-19.

16 Shen H, Wang D, Li L, Yang S, Chen X, Zhou S, Zhong S, Zhao J, Tang J: MiR-222 promotes drug-resistance of breast cancer cells to adriamycin via modulation of PTEN/Akt/FOXO1 pathway. Gene 2017;596:110-118.

-17 Zhang JY, Jin H, Wang GF, Yu PJ, Wu SY, Zhu ZG, Li ZH, Tian YX, Xu W, Zhang JJ, Wu SG: Methyl-1-hydroxy-2naphthoate, a novel naphthol derivative, inhibits lipopolysaccharide-induced inflammatory response in macrophages via suppression of NF-кB, JNK and p38 MAPK pathways. Inflamm Res 2011;60:851-859.

18 Li K, Wu JQ Jiang LL, Shen LZ, Li JY, He ZH, Wei P, Lv Z, He MF: Developmental toxicity of 2, 4-dichlorophenoxyacetic acid in zebrafish embryos. Chemosphere 2017;171:40-48.

19 Zhu Z, Zhao Y, Li J, Tao L, Shi P, Wei Z, Sheng X, Shen D, Liu Z, Zhou L, Tian C, Fan F, Shen C, Zhu P, Wang A, Chen W, Zhao Q, Lu Y: Cryptotanshinone, a novel tumor angiogenesis inhibitor, destabilizes tumor necrosis factor-alpha mRNA via decreasing nuclear-cytoplasmic translocation of RNA-binding protein HuR. Mol Carcinog 2016;55:1399-1410.

20 Marshall AD, Bailey CG, Champ K, Vellozzi M, O’Young P, Metierre C, Feng Y, Thoeng A, Richards AM, Schmitz U, Biro M, Jayasinghe R, Ding L, Anderson L, Mardis ER, Rasko JEJ: CTCF genetic alterations in endometrial carcinoma are pro-tumorigenic. Oncogene 2017;36:4100-4110. 


\section{Cellular Physiology Cell Physiol Biochem 2018;48:569-582 \begin{tabular}{l|l} 
DOI: 10.1159/000491886 & $\begin{array}{l}\text { O 2018 The Author(s). Published by S. Karger AG, Basel } \\
\text { www.karger.com/cpb }\end{array}$
\end{tabular} \\ Xu et al.: Liposomal Curcumin Targeting Endometrial Cancer}

21 Heudel PE, Fabbro M, Roemer-Becuwe C, Kaminsky MC, Arnaud A, Joly F, Roche-Forestier S, Meunier J, Foa C, You B, Priou F, Tazi Y, Floquet A, Selle F, Berton-Rigaud D, Lesoin A, Kalbacher E, Lortholary A, Favier L, Treilleux I, Ray-Coquard I: Phase II study of the PI3K inhibitor BKM120 in patients with advanced or recurrent endometrial carcinoma: a stratified type I-type II study from the GINECO group. Br J Cancer 2017;116:303-309.

-22 Qi Z, Wu M, Fu Y, Huang T, Wang T, Sun Y, Feng Z, Li C: Palmitic Acid Curcumin Ester Facilitates Protection of Neuroblastoma against Oligomeric A 440 Insult. Cell Physiol Biochem 2017;44:618-633.

23 Ahmad MZ, Alkahtani SA, Akhter S, Ahmad FJ, Ahmad J, Akhtar MS, Mohsin N, Abdel-Wahab BA: Progress in nanotechnology-based drug carrier in designing of curcumin nanomedicines for cancer therapy: current state-of-the-art. J Drug Target 2016;24:273-293.

24 Wang D, Veena MS, Stevenson K, Tang C, Ho B, Suh JD, Duarte VM, Faull KF, Mehta K, Srivatsan ES, Wang MB: Liposome-encapsulated curcumin suppresses growth of head and neck squamous cell carcinoma in vitro and in xenografts through the inhibition of nuclear factor kappaB by an AKT-independent pathway. Clin Cancer Res 2008;14:6228-6236.

25 Tang JC, Shi HS, Wan LQ Wang YS, Wei YQ: Enhanced antitumor effect of curcumin liposomes with local hyperthermia in the LL/2 model. Asian Pac J Cancer Prev 2013;14:2307-10.

26 Agashe H, Lagisetty P, Sahoo K, Bourne D, Grady B, Awasthi V: Liposome-encapsulated EF24-HP $\beta$ CD inclusion complex: a preformulation study and biodistribution in a rat model. J Nanopart Res 2011;13:2609-2623.

27 Saengkrit N, Saesoo S, Srinuanchai W, Phunpee S, Ruktanonchai UR: Influence of curcumin-loaded cationic liposome on anticancer activity for cervical cancer therapy. Colloids Surf B Biointerfaces 2014;114:349356.

28 Zhao J, Pan Y, Li X, Zhang X, Xue Y, Wang T, Zhao S, Hou Y: Dihydroartemisinin and Curcumin Synergistically Induce Apoptosis in SKOV3 Cells Via Upregulation of MiR-124 Targeting Midkine. Cell Physiol Biochem 2017;43:589-601.

29 Ruttala HB, Ko YT: Liposomal co-delivery of curcumin and albumin/paclitaxel nanoparticle for enhanced synergistic antitumor efficacy. Colloids Surf B Biointerfaces 2015;128:419-426.

30 Mondal G, Barui S, Saha S, Chaudhuri A: Tumor growth inhibition through targeting liposomally bound curcumin to tumor vasculature. J Control Release 2013; 172:832-840.

-31 Demchenko YN, Glebov OK, Zingone A, Keats JJ, Bergsagel PL, Kuehl WM: Classical and/or alternative NFkappaB pathway activation in multiple myeloma. Blood 2010;115:3541-3552.

32 Durand JK, Baldwin AS. Targeting IKK and NF-KB for Therapy. Adv Protein Chem Struct Biol 2017;107:77115. 